\title{
Escrita acadêmica: análise de uma pesquisa autoetnográfica desenvolvida no programa nacional de Mestrado profissional em Letras (PROFLETRAS)
}

\author{
Victoria Wilson*
}

\begin{abstract}
Resumo
O presente trabalho discute o processo de produção escrita acadêmica no âmbito dos estudos dos letramentos com base nos conceitos bakhtinianos de cronotopo e exotopia, com vistas a contribuir para um modo de ler o outro com empatia e acolhimento. Com dados oriundos de um recorte de uma pesquisa desenvolvida no programa de mestrado profissional em Letras (PROFLETRAS), o trabalho acompanha o percurso autoetnográfico assumido pela autora da dissertação na implementação de seu projeto de intervenção pedagógica com alunos do $7^{\circ}$ ano do Ensino Fundamental para, a partir do "excedente de visão", abordar as práticas de letramento vivenciadas neste estudo. A análise demonstrou o quanto, na busca de solução de problemas relativos às atividades propostas com os alunos, a professora ativava, em um processo dialógico, os conhecimentos e as experiências anteriores às "novas" práticas de letramentos acadêmicos. Neste duplo fazer, foi possível observar como os processos de letramentos "acontecem" e como estão vinculados a diferentes práticas de leitura, escrita e consciência linguística, bem como integrados a aspectos culturais e identitários. E, por fim, à medida que desenvolvia o projeto de intervenção em suas aulas, a professora-pesquisadora elaborava o seu projeto de pesquisa, o que resultou em um exercício de autoria, identidade e produção de conhecimentos (escolar e científico), refletindo-se, diretamente, na construção de sua escrita acadêmica.
\end{abstract}

Palavras-chave: Letramentos acadêmicos. Produção de conhecimento científico. Cronotopo. Exotopia.

\footnotetext{
* Universidade do Estado do Rio de Janeiro. Doutora em Letras. Professora do Curso de Letras e do Programa de Pós-Graduação em Letras (PPLIN e PROFLETRAS).ORCID https://orcid.org/0000-0002-5237-8860.
}

Cadernos CESPUC de Pesquisa. Série Ensaios. n.39, 20 Sem./2021, p. 185-201. e-ISSN: 2358-3231 (OJS). Recebido em: 25/10/2021. Aceito em: 02/12/2021. 


\title{
Academic writing: an analysis of an autoethnographic research developed in a national Master's degree professional program
}

\author{
Victoria Wilson
}

\begin{abstract}
This work discusses the academic writing production process in the realm of literacy studies based on the Bakhtinian concepts of chronotope and exotopy in order to contribute to a way of reading the other with empathy and outreach. The data came from part of a professional master's degree research developed in Languages (PROFLETRAS), and the work keeps track of the autoethnographic approach of the author to her thesis during the implementation of her project of pedagogic intervention with $7^{\text {th }}$ grade Primary School students to analyze literacy practices experienced during the study based on the concept of surplus of vision. The analysis showed how the teacher activated, within a dialogic process, the knowledge and previous experiences to the "new" academic literacy practices while searching for the solution to the activities put forward to the students. During this two-fold activity, it was possible to observe how literacy processes "take place" and how they are related to different reading, writing and linguistic awareness practices, as well as integrated into cultural and identity aspects. Finally, while the teacher-researcher developed her intervention project in her classes, she elaborated her research project, which resulted in an exercise of authorship, identity and production of knowledge (educational and scientific), and this was directly reflected on the construction of her academic writing.
\end{abstract}

Keywords: Academic literacy. Production of scientific knowledge. Chronotope. Exotopy. 


\section{Introdução}

Os desafios da formação docente são muitos, e perpassam diversificados aspectos, no que tange aos letramentos acadêmicos de alunos de graduação e pós-graduação, para que sejam proficientes, atuantes, críticos e reflexivos. Esse desafio envolve distintos eixos (leitura, escrita, oralidade e consciência linguística) relativos a cada campo disciplinar e orientadores do trabalho pedagógico. Mais especificamente quanto à escrita acadêmica, a legibilidade e a legitimidade das compreensões dos alunos, suas experiências com a linguagem e o modo como se expressam em suas produções escritas revelam outros conhecimentos e outras racionalidades distintas, muitas vezes, dos esperados e "desejados" na academia. Um dos desafios dos professores, portanto, é o de enfrentar e lidar com uma diversidade de conhecimentos e racionalidades, no ambiente acadêmico. Boaventura de Sousa Santos nos lembra que "todos os conhecimentos sustentam práticas e constituem sujeitos” (SOUSA SANTOS, 2010, p.30). Portanto, como ler o outro de forma a acolher outros discursos ao mesmo tempo em que se ensinam outras habilidades e competências da chamada escrita acadêmica? Ou, considerando as reflexões de Arroyo (2011, p.150): "Mas que experiências e que sujeitos reconhecer como produtores de indagações e de conhecimentos?"

$\mathrm{Na}$ concepção dialógica bakhtiniana, o outro nos constitui. São os outros que compõem os arquivos de nossas experiências e conhecimentos dos distintos círculos sociais e das diferentes esferas da vida. E são os outros que também nos leem; os destinatários de nossos discursos e valores: eu leio o outro que também me lê. E na vida dos gêneros do discurso, esses que são lidos, ensinados e escritos, na academia, sofrem o peso e o valor do destinatário e, assim, reformula-se o próprio estilo do gênero.

Este trabalho, pois, parte do pressuposto de que os letramentos acadêmicos, ainda que sofram um processo de "pasteurização" e coerção normativa, próprio das determinações institucionais e disciplinares, são afetados por outras ordens, outras compreensões e racionalidades, outras visões de mundo que vão configurando e reconfigurando outras formas de conhecimento e produzindo (novos) sentidos na escrita dos alunos (GOULART; WILSON, 2019; WILSON, 2019). Nas últimas décadas, a 
contribuição dos Novos Estudos do Letramento (LEA; STREET, 1998; STREET, 2004; STREET, 2014) e os Multiletramentos, e de proposições centradas no modelo ideológico de letramento, entendido como prática social de leitura e escrita, surge como proposta renovada de ensino no contexto acadêmico (haja vista os estudos dos letramentos acadêmicos). No entanto, estudos sugerem o quanto é preciso avançar nas práticas de letramento acadêmico no que tange o trabalho pedagógico, especialmente, com o ensino da leitura e escrita, considerando, dentre outros fatores, práticas e discursos que circulam e que são específicos dos contextos acadêmicos e suas especialidades, as referências à escrita e a outras semioses, as experiências subjetivas com diferentes gêneros discursivos e linguagens, os letramentos de origem, a circulação social dos alunos, em sentido amplo, e sua inserção acadêmica; a projeção identitária no processo de letramento, as expectativas docentes em relação à formação prévia dos alunos, dentre outros fatores.

Neste cenário, e com vistas a contribuir com essa discussão, este trabalho apresenta dados oriundos de uma pesquisa inspirada na autoetnografia como metodologia, desenvolvida por uma aluna do programa nacional do Mestrado Profissional em Letras (PROFLETRAS), pela Faculdade de Formação de Professores da Universidade do Estado do Rio de Janeiro (FLORENTINO, 2020). Nosso objetivo é, com base nas propostas e discussões ali apontadas, fomentar uma reflexão sobre os letramentos acadêmicos e escolares a partir do modo de "olhar" o outro, na perspectiva do "excedente de visão" (BAKHTIN, 2003, p. 23). Assim, esperase acolher as práticas de letramento como fonte de conhecimento e saber legítimo, para, a partir desse acolhimento, tratá-las e ensiná-las como fonte de sentido e experiência, considerando o dialogismo bakhtiniano "como qualquer acontecimento que envolva sujeitos em interação discursiva." (BRAIT, 2012, p. 87).

\section{Semeando o campo: costurando método e análise}

Cronotopo e exotopia, dois conceitos de Bakhtin, primeiramente concebidos no âmbito da atividade estética e, segundo Amorim (2006), 
estendidos às atividades de pesquisa em Ciências Humanas, são utilizados neste trabalho, associados à heterocientificidade, outro conceito bakhtiniano de orientação metodológica nesta área. Serão utilizados como método de análise e com vistas à análise dos letramentos acadêmicos, em interface com os letramentos escolares, a partir de um recorte de uma dissertação desenvolvida no âmbito do Programa de Mestrado Profissional em Letras (PROFLETRAS), campus da Faculdade de Formação de Professores da UERJ. Segundo Geraldi:

Assumir a heterocientificidade implica abandonar a posição epistemológica que somente admite como científico (e verdadeiro dentro de cada teoria) o enunciado relativo àquilo que se repete, àquilo que é imutável, àquilo que é produto da abstração deduzidas todas as particularidades, todas as singularidades como “desvios” não significativos da realidade concreta (GERALDI, 2012, p.20).

A forma de olhar o outro a partir de um lugar exterior é o sentido básico de exotopia e vai ao encontro da concepção de uma prática de letramento que visa desfazer uma tradição hegemônica, em geral, uma visão ocidentalizada de letramento e sua escolarização, baseada em relações de poder e concentrada em si mesma (STREET, 2014). Fixada em si, nada vê do outro, a não ser a si mesma: seus próprios valores e conhecimentos, seus ritos, seus costumes que, assim, se sobrepõem e se impõem aos valores, ritos, costumes, experiências e saberes alheios. Nesta ótica, só há lugar para um tipo de letramento, o autônomo; e não para práticas de letramento socializadas, como a que propomos, que busquem olhar o outro a partir do "excedente de visão" a que Bakhtin se refere, isto é:

Eu devo entrar em empatia com esse outro indivíduo, ver axiologicamente o mundo de dentro dele tal qual ele o vê, colocar-me no lugar dele e, depois de ter retornado ao meu lugar, completar o horizonte dele com o excedente de visão que desse meu lugar se descortina fora dele, convertê-lo, criar para ele um ambiente concludente a partir desse excedente de minha visão, do meu conhecimento, da minha vontade e do meu sentimento (BAKHTIN, 2003, p. 23).

O conceito de exotopia traz a ideia de acabamento, de construção do todo, como se refere Amorim (2006), por isso, está ligado à dimensão 
espacial. Já o conceito de cronotopo está vinculado à dimensão temporal e histórica; onde os sujeitos se inscrevem e escrevem suas histórias. Para Amorim, "[...] no trabalho de análise dos discursos e da cultura, quando conseguimos identificar o cronotropo de uma determinada produção discursiva, poderemos dele inferir uma determinada visão de mundo" (2006, p.106). Nesse sentido, exotopia e cronotopo se fundem como método, pois o acolhimento ao outro significa entrar em empatia com ele a partir do "excedente de visão" para interpretar seus movimentos, seus conhecimentos e suas experiências, até as suas transformações, enfim, o cronotopo para, então, "inferir uma determinada visão de homem", conforme Amorim (2006, p. 106).

A visão de mundo que se pretende descortinar neste trabalho, inspirada nos conceitos de cronotopo e exotopia, orienta-se para as formas (práticas de letramento) com que Florentino (2020), em sua dissertação, semeia o chão da sala de aula em articulação com o campo teórico de sua pesquisa para planejar e executar seu projeto de intervenção pedagógica como "produto" do mestrado profissional. Com foco na escrita e reescrita de textos produzidos por alunos do $7^{\circ}$ ano do Ensino Fundamental, em uma escola pública do município de Macaé, RJ, a autora, professora-pesquisadora, opta pela abordagem autoetnográfica para conduzir seu projeto. Decidir por esta metodologia foi uma forma de a autora se identificar neste processo em que ora se sentia atuando como professora - que era/é -, ora se via como pesquisadora como ela mesma afirma:

Decidir, portanto, pela pesquisa autoetnográfica, com base na etnografia confere ao meu trabalho o olhar de retratista e retratado, outorgando autonomia para gerir decisões quanto às necessidades de minha sala de aula e, mais ainda, confere a mim, professora/pesquisadora, a oportunidade de participar desse processo de forma a avaliar o meu fazer pedagógico, vivendo duplamente as condições/ funções de professora e pesquisadora (FLORENTINO, 2020, p.26).

De acordo com Corrêa (2011), o discurso é elemento estruturadorestruturante das relações de ensino e de aprendizagem e a linguagem em uso se configura como o "espaço em que as pessoas se fazem sujeitos no processo discursivo" (CORRÊA, 2011, p.340). Considerando o discurso no sentido atribuído por Corrêa e compreendendo a linguagem como 
locus no qual as pessoas se fazem sujeitos, trilharemos com Florentino o percurso autoetnográfico de sua pesquisa, observando o que discursos e vozes expressam em termos de práticas de letramento, na análise do capítulo de sua dissertação, que antecede as considerações finais, intitulado: "Autoetnografia: o tempo e o espaço nessa pesquisa".

No processo de escrita acadêmica, a autora tinha como meta a elaboração de atividades didáticas, em que incorporava os modelos teóricos aprendidos (em aprendizagem) no curso das disciplinas do mestrado, bem como aqueles definidos para fazerem parte do corpo teórico de sua pesquisa, além daqueles que constituíam seus letramentos anteriores e suas experiências e com os quais ela se identificava. Muitas vezes, os novos saberes e suas linguagens conflitavam com saberes e práticas já sedimentados e naturalizados. Era preciso enfraquecer resistências para semear o solo com novas "ferramentas", seja em aliança, seja em conflito com as antigas. Portanto, a professora se sentia duplamente desafiada em meio aos dilemas que surgiam neste percurso e que configurariam, a partir de então, seu processo de letramento acadêmico.

Os letramentos, sejam os acadêmicos, sejam os escolares, não estão desvinculados dos contextos nos quais se inserem, e a própria noção de contexto pode ser entendida de modo dinâmico e alargado: os contextos não estão encapsulados e estão sujeitos às interpretações recíprocas dos sujeitos. Por outro lado, a perspectiva (auto)etnográfica e discursiva adotada na dissertação de Florentino permitiu que as suas práticas de letramento acadêmico (e a elaboração e reelaboração de sua escrita, inclusive) fossem vividas como experiências em processo, suscetíveis a mudanças.

O que parecia, a princípio, um obstáculo assustador, isto é, lidar com dilemas, contradições e imprecisões ao longo do trabalho, tornou-se a origem de novos desafios, atuando como fonte de experiência subjetiva e fonte de novos conhecimentos - como algo que diz respeito então às subjetividades e identidades, algo que está dentro de cada um de nós e não se aloja fora de nós -, e é vivido como "autênticas" práticas de letramento. As concepções de escrita acadêmica estão, portanto, alinhadas à linguagem em uso, a práticas sociais nas quais os sujeitos estão envolvidos e engajados em um projeto que deve fazer sentido em e para suas vidas. 


\section{O campo: semear e colher}

No capítulo "Autoetnografia: o tempo e o espaço nessa pesquisa", Florentino (2020) teve a oportunidade de retomar (e se "apossar" de) a orientação metodológica adotada - a autoetnografia -, e discorrer sobre sua experiência acadêmico-profissional na condução de suas atividades didáticas em seu projeto de intervenção pedagógica com os alunos. $\mathrm{O}$ capítulo, diferentemente dos demais, é o espaço-tempo em que a autora, trabalhando também com os conceitos de cronotopo e exotopia, pôde mostrar (-se) seus encontros e desencontros; seus encantos e desencantos $\mathrm{e}(\mathrm{m})$ sua busca incessante para construir dois projetos, na verdade: $\mathrm{o}$ projeto dissertativo propriamente dito e o projeto de intervenção pedagógica com os alunos, ambos constituindo a sua dissertação. $\mathrm{Na}$ introdução deste capítulo, Florentino faz a seguinte consideração:

Sendo a minha participação nesse trabalho como professora pesquisadora, sendo eu, portanto, também integrante do grupo pesquisado, é de suma importância a existência desse capítulo cuja pretensão é registrar as minhas impressões e reflexões acerca do que foi pesquisado; as transformações pelas quais passei e por que passei; o que aconteceu comigo durante esse processo; como entrei e como saí dessa pesquisa. Alimentada pela pesquisadora, a professora volta preenchida e transformada. (FLORENTINO, 2020, p.119).

No afã de trabalhar a produção da escrita e da reescrita com alunos do $7^{\circ}$ ano do Ensino Fundamental, em uma escola pública do Estado do Rio de Janeiro, na perspectiva dialógica de raiz bakhtiniana, a professora se preocupava, inicialmente, com as normas gramaticais como forma de aprimorar a competência escrita dos alunos. No entanto, foi observando que havia, no processo de letramento dos alunos, algo mais que a aprendizagem de regras gramaticais centradas na correção linguística, que dá início às suas indagações, a saber:

Contudo, eu sabia que não eram as regras nem as normas gramaticais e ortográficas por si só que colocariam meus alunos em comunhão com o ambiente social mais amplo de suas relações. Tampouco seriam essas regras as principais 
possibilidades de envolvimento com a escrita. Era preciso mais do que isso. Mas o quê, exatamente? (FLORENTINO, 2020, p.119).

"Mas o quê, exatamente?" diante do dilema em que se encontrava, foi através de novas leituras que buscou respostas e traçou uma metodologia de ensino de modo que seus alunos pudessem se envolver no processo de produção escrita e rescrita como experiência de trabalho e fonte de sentido. Ao mesmo tempo em que refazia o caminho (teórico e metodológico) com os alunos, trilhava os seus, construindo-se e desconstruindo-se, em uma experiência compartilhada mutuamente. Segundo Ivanic (1998, p.67), práticas, compreendidas como normas de um grupo, e discursos, no âmbito dos estudos do letramento, não são entidades fixas, mas estão em fluxo constante. Sobre práticas de letramento, a autora pontua que:

Literacy practices are a person's or group's responses to a particular life demand which involves written language in some way. [...] Literacy practices include not only mental process and strategies, but also decisions such as whether to employ written language at all, which types of writing reading and writing to engage in, discourse choices, feelings, attitudes, and practical, physical activities and procedures associated with written language.

Literacy practices of all these types are both shaped by and shapers of people's identity: acquiring certain literacy practices involves becoming a certain type of person. ${ }^{1}$ (IVANIC, 1998, p.67).

Neste percurso, nota-se como a professora-pesquisadora, motivada pela demanda de ser bem sucedida em suas propostas de atividades com os alunos na produção de escrita e reescrita, buscava se conectar com "algo mais", além dos aspectos textuais, também importantes para a correção linguística, a saber, o envolvimento dos alunos nas atividades. Neste processo, ambos, professora e alunos, construíam suas atividades de letramento e, nesta construção, desenvolviam experiências linguísticas, cognitivas, discursivas e afetivas; engajavam-se no projeto e este engajamento refletia-se

\footnotetext{
1 Práticas de letramento são as respostas de um grupo ou de um indivíduo a uma dada exigência social que envolva de alguma forma a língua escrita. [...] As práticas de letramento abrangem não só estratégias e processos mentais, mas também decisões a respeito de se empregar ou não a língua escrita, quais tipos de escrita e leitura serão utilizados, escolhas discursivas, sentimentos, atitudes, atividades físicas e pragmáticas, além de procedimentos relacionados à língua escrita. As práticas de letramento aqui mencionadas são formadas pela identidade do indivíduo e ao mesmo tempo formadoras de tal identidade: dominar determinadas práticas de letramento implica se tornar um determinado tipo de pessoa. (IVANIC, 1998, p. 67, tradução nossa).
} 
no comportamento de cada um em sala de aula, bem como ia influenciando na transformação de cada um como pessoa.

A resposta veio a partir de muitas práticas de desconstrução e reconstrução da professora/ pesquisadora e também dos alunos; uma situação bastante diferente de outras já vividas na sala de aula, através da qual pude vivenciar as minhas dores e as dos meus alunos, como se num processo metalinguístico e metavivencial/ metaexperimental. Perceber as minhas limitações, inclusive com relação à escrita da minha dissertação, possibilitou-me compreender ainda mais o distanciamento que havia entre o meu aluno e a sua escrita, já que essa relação era pautada, dentro da esfera escolar, na priorização de atividades linguísticas e metalinguísticas dissociadas das experiências pessoais com a linguagem. Entender que era preciso substituir a ideia de que se escreve para ser corrigido pela ideia de que se escreve para ser lido foi fundamental para mudar significativamente a atitude dos alunos diante das propostas de produção textual. (FLORENTINO, 2020, p.119).

Considerando a mudança de atitude da autora frente a uma visão de escrita na escola que valoriza a correção no lugar da recepção do texto na passagem em que ela afirma que "entender que era preciso substituir a ideia de que se escreve para ser corrigido pela ideia de que se escreve para ser lido foi fundamental para mudar significativamente a atitude dos alunos diante das propostas de produção textual.", é possível verificar como este aspecto pontual se reflete no global. Trata-se de uma mudança significativa em termos das práticas de letramento escolares e acadêmicas, uma vez que repercutiu tanto no ambiente escolar propriamente dito quanto na escrita da pesquisa acadêmica.

A consciência da autora, ao declarar sobre o seu processo de desconstrução e reconstrução de práticas, condutas e organização do conhecimento como uma metavivência e metaexperiência confirma o que vários estudiosos sobre letramento acadêmico, conforme já demonstrado em Ivanic (1998), apontam, isto é, a relação entre letramento e construção de identidade(s). Zavala, por exemplo, mostra como, no processo de letramentos acadêmicos, "as formas de escrita caminham juntas às formas de pensar e as operações cognitivas envolvidas são, por sua vez, inseparáveis da compreensão subjetiva e contextualizada que a pessoa faz do mundo" (ZAVALA, 2010, p.81). Nas pesquisas em letramento acadêmico, há um 
entendimento segundo o qual as práticas discursivas estão ancoradas no contexto e são adaptadas e renovadas em função das interações entre os sujeitos em suas atividades nestes espaços, desconstruindo uma ideia de superioridade das operações cognitivas (modelo de letramento autônomo) sobre as sociais e interacionais.

Em estudos sobre letramento acadêmico, Wilson (2019) também destaca como as pesquisas e as escritas acadêmicas dos estudantes são atravessadas pelas experiências linguísticas de cada um, ou seja, seus letramentos de origem em contato com os novos letramentos; pelas relações de poder devido ao peso do destinatário (quem é o professor que "me" lê, que "me" avalia), e como os letramentos estão menos submetidos a sistemas abstratos de regras e mais vinculados a vivências cotidianas, aos contextos reais de comunicação no interior das comunidades de práticas onde são sentidas como deslocadas ou próprias.

Mais do que exercícios cognitivos, práticas de letramento são resultantes de atividades sociais e socializantes, dizem respeito às pessoas e aos modos como essas pessoas agem sobre e com a língua(gem) e o mundo, ainda que o mundo seja a sala de aula e uma pesquisa científica. No processo de realização da pesquisa com os alunos, concomitantemente ao momento de reflexão e atualização dos conhecimentos, Florentino se deslocava em seus papeis de professora-pesquisadora e vice-versa, reformulando sua prática pedagógica e vivenciando os múltiplos movimentos desse processo. Mais um momento/movimento em que a teoria semeou a prática, reformulando-a. Para ilustrar o quanto alterou e reelaborou seu projeto, reproduzimos abaixo outra passagem:

Houve, portanto, uma mudança de postura da professora/pesquisadora para que os alunos também modificassem o seu olhar em relação à produção de seus próprios textos. Deixamos de considerar a escrita como produto e passamos a considerá-la um processo. (FLORENTINO, 2020, p.120).

No entanto, a autora salienta o quanto as práticas de letramento são alimentadas pela força da consciência, da consciência crítica, como propõe Paulo Freire em prol de uma educação libertadora, crítica e transformadora. O poder de transformação da realidade é dialógico neste sentido, pois ambos, educador e educando, precisam se reconhecer "verdadeiramente" neste 
processo, o que implica uma atitude responsiva. Para Bakhtin, "a expressão do enunciado, em maior ou menor grau, responde, isto é, exprime a relação do falante com os enunciados do outro, e não só a relação com os objetos de seu enunciado" (BAKHTIN, 2003, p.298, grifo do autor). Neste relato, é possível observar o quanto a pesquisadora incorporou a autoetnografia como um método capaz de guiá-la com segurança, dando-lhe a confiança necessária para assumir as limitações, as idas e vindas, os riscos que caracterizam o educar, o ensinar, como ato de (auto)escuta permanente que lhe permitiram avançar e abrir-se para múltiplos olhares, perspectivas diversas que também encontrou em seus alunos. Afirma, então, que:

Para que isso fosse possível, durante todo o processo de intervenção, a professora e a pesquisadora se alternavam constantemente num exercício de deslocamento, tanto por parte da professora/pesquisadora quanto dos alunos, no tempo e no espaço, para que outras perspectivas acerca das ações realizadas aparecessem. Assim, através dessa pesquisa compreendi o quanto foi fundamental para os sujeitos envolvidos movimentarem-se em direções diversas, sob perspectivas diversas para que esse movimento lhes permitisse novos olhares, permitindolhes, também, avaliar e reformular a própria prática pedagógica e discente (FLORENTINO, 2020, p.122).

Cronotopo e exotopia. Tempo e espaço atuando em conjunto na modelação de novos sujeitos em suas histórias e movimentos. Para corroborar o quanto o quadro teórico da dissertação foi também vital para a transformação da professora-pesquisadora em sua trajetória, destacamos o trecho abaixo que confirma uma mudança de atitude diante de suas ações, que reverberaram também mudanças nos letramentos escolares. À medida que as resistências se afrouxavam, abria-se espaço para a germinação de novos deslocamentos e novas atitudes, como ela mesma declara. A professora, "afetada" pela perspectiva dialógica da linguagem (e da vida, por que não?), acolhia-se na mesma medida em que acolhia o outro em seu fazer. Ambos, professor e alunos, assumiam o protagonismo de suas ações e tornavam-se autores de suas histórias, reescrevendo seus letramentos, como se lê a seguir: 
O primeiro texto que me permitiu esse deslocamento foi o do aluno M. no qual ele desabafa o quanto não gostava de escrever porque seus textos não eram lidos, eram corrigidos. Ler isso numa de suas redações revelou-me três descobertas importantes na minha posição de pesquisadora: que a interlocução e o dialogismo existem, que são fundamentais numa sala de aula e imprescindíveis para o processo de escrita e de reescrita. Esse episódio revelou à pesquisadora que aquela nova postura da professora de explicar ao aluno que textos existem para serem lidos, revisados e reescritos porque foram feitos para afetar o outro ou a si mesmo, mudou significativamente as nossas experiências, pois essa nova atitude fazia deles sujeitos-autores. Sendo assim, escrever para eles, tornou-se um momento de construção, de protagonismo e aos poucos o processo de reescrita passou a ser cada vez mais constante para esses alunos, que também começavam a descobrir a importância da discursividade. (FLORENTINO, 2020, p.124).

Neste rico relato autoetnográfico, Florentino mescla suas experiências de letramento acadêmico às escolares. A mudança de postura da professora (e a de seus alunos) não ocorreu nem de forma simples, nem linear. Ao contrário, como acompanhamos na leitura desses trechos, a mudança envolveu profundas transformações, seja nas questões de identidade, seja nos aspectos relativos aos conhecimentos. Aqui, temos o indício do que é preciso levar em conta sobre as percepções individuais e locais e em que medida não devemos "impor uma visão 'forasteira' de letramento" (STREET, 2014, p.47) sobre essas percepções. Olhar o outro para acolhê-lo em suas experiências, não para delas expropriá-lo.

As propostas para as produções consideravam o dialogismo proposto por Bakhtin, o endereçamento e a compreensão responsiva. E foi assim que começaram a "aparecer" os textos que mudariam significativamente a minha postura diante das produções textuais dos meus alunos e que me deslocariam da posição de professora para pesquisadora e vice-versa num movimento exotópico através do qual eu me posicionaria entre dois pontos de vista diferentes. Como num susto, eu me percebi olhando a minha prática por outro ângulo; (...) (FLORENTINO, 2020, p.125).

Segundo Zavala, é preciso entender o letramento como "uma forma de ver o mundo" (ZAVALA, 2010, p.92). Ao que tudo indica, Florentino se 
encontrou e nesse encontro o mundo se revelou, dialogicamente, para ela e seus alunos. Ao invés da imposição, o letramento acadêmico foi vivido, mexido e remexido, vivenciado como um processo. Segundo Street,

Há um argumento adicional, trazido à tona no trabalho de Luke e Freebody e central para o modelo ideológico de letramento: o de que aprender o letramento não é simplesmente adquirir conteúdo, mas aprender um processo. Todo letramento é aprendido num contexto específico de um modo particular e as modalidades de aprendizagem, as relações sociais dos estudantes com o professor são modalidades de socialização e aculturação (STREET, 2014, p.154).

A percepção de Florentino sobre a escola e o papel do professor como agenciador de mudanças também ficou muito clara. Ficou evidente, também, que as modalidades de aprendizagem, bem como as relações sociais estabelecidas entre professor e estudantes aconteciam reciprocamente; e que os processos de socialização e aculturação eram produzidos neste percurso: não como imposições, mas como apropriações, reapropriações (ainda que sofridas, inicialmente), sujeitas a reformulações, de onde resultou uma colheita rica e generosa.

Contudo, a escola, de maneira geral, ainda não passou por essa metamorfose pela qual passei. Sendo assim, a metodologia usada nesta pesquisa foi de grande contribuição para que meus alunos e eu pudéssemos experienciar uma nova relação com a linguagem e, sobretudo, uma nova relação com a situação de produção textual escrita que passou pela interlocução e pela compreensão responsiva, desencadeando no sujeito-autor uma atitude espontânea e consciente neste movimento contínuo de escrita e reescrita (FLORENTINO, 2020, p.126).

\section{Colhendo os resultados}

Diz Fiorin acerca de Bakhtin que "o caráter fundamentalmente dialógico de todo enunciado do discurso impossibilita dissociar do funcionamento discursivo a relação do discurso com seu outro." (FIORIN, 2006, p.191). Neste trabalho, por meio dos conceitos de cronotopo e exotopia, 
tomados como método, foi possível observar o outro e seus movimentos com e através dos discursos (escritos) produzidos academicamente. "É na relação com o discurso do Outro, que se apreende a história que perpassa o discurso" (FIORIN, 2006, p.191) afirma Fiorin, uma vez que para este autor, a História, na filosofia bakhtiniana, "não é algo exterior ao discurso, mas é interior a ele, pois o sentido é histórico.” (FIORIN, 2006, p.192).

A história que testemunhamos e tentamos captar do retratado "é aquela que vive cada instante de sua vida como inacabado, como devir incessante" (AMORIM, 2006, p.96). Procuramos captar os momentos vividos por Florentino como movimentos em acabamento: as idas e vindas da professora-pesquisadora, as construções, desconstruções e reconstruções incessantes caracterizaram o seu (duplo) fazer, pois, à medida que desenvolvia o projeto de intervenção em suas aulas, a professorapesquisadora elaborava o seu projeto de pesquisa simultaneamente.

Foi na tensão entre estas duas ações que os processos de letramentos aconteciam - vivenciados pela professora-pesquisadora (e vice-versa) e pelos alunos na relação que se estabeleceu entre eles. $O$ resultado deste processo se constitui como um amálgama de experiências - vivenciadas de dentro para fora - e não como algo exterior a elas. Os letramentos, do ponto de vista das práticas sociais, especialmente o letramento acadêmico aqui abordado, foram resultantes do exercício constante de autoria, identidade e produção de conhecimentos (escolar e científico), refletindose, diretamente, na construção da escrita acadêmica de Florentino (2020).

Portanto, uma das contribuições deste trabalho foi o do alinhamento a novas compreensões "do que conta como conhecimento relevante dentro e através das disciplinas, com a abertura das concepções da escrita acadêmica a novas formas de significar" (ZAVALA, 2010, p.92). Mas, também, de se significar, pois, na abertura ao ingresso de outros domínios como o das emoções, da intimidade, do senso comum etc. (ZAVALA, 2010, p.92), e de distintos modos de ser letrado, e, graças à autoetnografia, em seu compromisso de considerar as perspectivas e experiências dos sujeitos, é possível chegar à compreensão de outras experiências culturais e identitárias.

Assumir a heterocientificidade implica abandonar a posição epistemológica que somente admite como científico (e verdadeiro dentro de cada teoria) o enunciado relativo àquilo que se repete, àquilo que é imutável, àquilo que é produto da abstração deduzidas todas as particularidades, todas 
as singularidades como "desvios" não significativos da realidade concreta (GERALDI, 2012, p.20).

Em sua "árdua" trajetória, Florentino conseguiu se ver, para, ao se ver, conseguir olhar o outro.

\section{Referências}

AMORIM, M. Cronotopo e exotopia. In: BRAIT, B. (org.). Bakhtin: outros conceitos-chave. São Paulo: Editora Contexto, 2006. p. 95-114.

ARROYO, M. Currículo, território em disputa. Petrópolis: Editora Vozes, 2011.

BAKHTIN, Mikhail. Estética da Criação Verbal.Tradução de Paulo Bezerra. São Paulo: Martins Fontes, 2003.

BRAIT, Beth. Alteridade, dialogismo, heterogeneidade: nem sempre o outro é o mesmo. Revista brasileira de psicanálise. São Paulo, v. 46, n. 4, p. 8597,dez.2012.Disponívelem:http://pepsic.bvsalud.org/scielo.php?script=sci_ arttext\&pid=S0486641X2012000400008\&lng=pt\&nrm=iso. Acesso em: 15 set. 2016.

CORRÊA, M. L. G. As perspectivas etnográfica e discursiva no ensino da escrita: o exemplo de textos de pré-universitários. Revista da ABRALIN, v. 10, n. 4, 31 dez. 2011. Disponível em: https://revista.abralin.org/index.php/ abralin/article/view/1115/1038. Acesso em: 15 set. 2016.

FIORIN, J. L. Interdiscursividade e intertextualidade. In: BRAIT, B. (org.). Bakhtin: outros conceitos-chave. São Paulo: Editora Contexto, 2006. p.161-194.

FLORENTINO, S. A reescrita na sala de aula e o dialogismo na construção do sujeito-autor. 2020. 150 f. Dissertação (Mestrado Profissional em Letras) - Faculdade de Formação de Professores, Universidade do Estado do Rio de Janeiro, São Gonçalo, 2020. 
GERALDI, J. W. Heterocientificidade nos estudos linguísticos. Palavras e contrapalavras: enfrentando questões da metodologia bakhtiniana. São Carlos: Pedro \& João Editores, 2012. p.19-39.

GOULART, C.; WILSON, V. Letramento acadêmico: construção de conhecimentos e de identidades. In: SILVA, J. Q. G.; LOPES, M. A. P. T. (org.). Práticas discursivas em letramento acadêmico: questões em estudo. Entrevistas sobre a escrita acadêmica. v. 2. Belo Horizonte: Editora PUC Minas, 2019. p. 108-130.

IVANIC, R. Writing and identity: the discoursal construction of identity in academic writing. Amsterdam, Philadelphia: John Benjamins Publishing, 1998.

LEA, M.; STREET, B. V. Studies in Higher Education. v. 23, n. 2, 1998. p. 157-173.

SOUSA SANTOS, B. Um discurso sobre as ciências. São Paulo: Cortez, 2010.

STREET, B. V. Los nuevos estudios de literacidad. In: ZAVALA, V.; NIÑOMURCIA, M.; AMES, P. (eds.). Escritura y sociedad: nuevas perspectivas teóricas y etnográficas. Lima: Rede para el Desarrollo de las Ciencias Sociales em el Perú, 2004. p. 81-108.

STREET, B. V. Letramentos sociais. São Paulo: Parábola, 2014.

WILSON, V. O professor e a pesquisa: a experiência com a escrita na universidade. In: SCRIPTA, Belo Horizonte, 2019, v. 23, n. 48, p. 41-52.

ZAVALA, V. Quem está dizendo isso?: letramento acadêmico, identidade e poder na educação superior. In: VOVIO, C.; SITO, L.; DE GRANDE, P. (org.). Letramentos: rupturas, deslocamentos e repercussões em pesquisas em linguística aplicada. Campinas, São Paulo: Mercado de Letras, 2010. p. 71-98. 